\title{
Pros and Cons of Direct Oral Anticoagulants versus Vitamin K Antagonist
}

\author{
Adel Ekladious ${ }^{1,2, *}$ \\ ${ }^{1}$ Associate Professor of Medicine, Faculty of Health and Medical Sciences, University of Western Australia, Australia \\ ${ }^{2}$ Bega- south East Regional Hospital, NSW, Australia
}

*Corresponding authors: Adel Ekladious, Associate Professor of Medicine, Faculty of Health and Medical Sciences, University of Western Australia, 35/ Stirling Highway, Perth Western Australia 6009, Australia, Tel: 61499449905; E-mail: ekladiou@gmail.com

Received: 24 Aug, 2021 | Accepted: 01 Oct, 2021 | Published: 09 Oct, 2021

Citation: Ekladious A (2021) Pros and Cons of Direct Oral Anticoagulants versus Vitamin K Antagonist. J Clin Case Stu 6(5): dx.doi. org/10.16966/2471-4925.236

Copyright: (C) 2021 Ekladious A. This is an open-access article distributed under the terms of the Creative Commons Attribution License, which permits unrestricted use, distribution, and reproduction in any medium, provided the original author and source are credited.

\section{Introduction}

Direct Oral Anticoagulants (DOSCS) had become a standard practice since been approved in 2010 and almost replaced warfarin in medical and surgical patients [1]. Unlike warfarin, DOSCS have a set dose and do not require regular international normalization ratio blood testing, they also have faster onset and offset action which make it safer. Warfarin has a long half-life and narrow therapeutic window, necessitating regular blood monitoring and is a very common cause of iatrogenic hospital admission, management of perioperative anticoagulation for patients on direct anticoagulants became simple, standardized and patient does not need to hospital admission before elective surgery.

\section{Discussion}

DOSCS either antithrombin (dabigatran) or factor Xa inhibitor (apixaban, rivaroxaban, edoxaban and betrixaban)

Patient make a quick decision to go for DOSCS anticoagulation over warfarin as doses are fixed, and no need to do blood testing for monitoring and there is decreased risk of bleeding especially hemorrhagic stroke [2], again switching from warfarin to DOSCS is easy and safe given that the half-life of dabigatran, apixaban, edoxaban and rivaroxaban is 12 hours in the presence of normal kidney function, where betrixaban is 24 hours [3].

Dabigatran is $85 \%$ renally excreted that is why half-life is up to 48 hours in patients with creatinine between $30-50 \mathrm{ml} / \mathrm{min}$, other advantage of DOSCS that when going for procedures with low risk of bleed (endoscopy with no biopsies or dental work) there is no need to cease DOSCS.

Procedures with mild risk of bleed in the presence of normal kidney and liver function, DOSCS will be stopped only 24 hours before and restarted 6 hours after surgery [4].

High bleeding risk like spinal surgery, patient need to stop anticoagulants 3-5 days and restart 48 hours after the procedure [5] bleeding risk can be assessed by age, impaired kidney function, concomitant use of non-steroidal anti-inflammatory, antiplatelet, history of hemorrhagic stroke, dissecting aneurism, bleeding or coagulation disease, uncontrolled hypertension, liver failure, use of cytochrome P450 induce medication [6].

In October 19, 2010 FDA approval had been granted for dabigatran for non-valvular AF, treatment and prevention of DVT and PE, thromboprophylaxis after total hip replacement, off-label indication includes thromboprophylaxis after total knee replacement and after PCI with non valvular AF, rivaroxaban was granted approval for after total knee and hip replacement, prophylaxis in ill medical patients, and peripheral vascular diseases, apixaban granted approval for same indication [7].

DOSCS do not bind with platelet factor 4 (anti heparin) that is why it does not cause HIT (heparin induced thrombocytopenia), in fact it is a treatment option for HIT [8].

Patient with high BMI (40) will have less exposure of the drugs which increase thrombosis risk and patient with low BMI will have more exposure for the drugs and increased the bleeding risk [9].

Patient who started on dabigatran will have less risk of brain hemorrhage and probably slightly increase in gastrointestinal bleed with the higher dose $150 \mathrm{mg}$ BD compared with warfarin [10]. Common side effect of dabigatran is dyspepsia and gastroesophageal reflux [11].

With direct factor $\mathrm{X}$ inhibitor, drug monitoring can be done by measuring anti factor $\mathrm{X}$ inhibitor specially in patients with extreme weight, slim Asian patients should not prescribe lower doses as the Korean study did not support that [12]. Patient who develops non-lifethreatening bleed due to DOACs, do not require reversal treatment because half-life of DOACs is short (12 Hours) especially in the presence of normal kidney and liver function [13]. In life threatening bleed due to dabigatran, patient can be treated with hemodialysis or hemofiltration. Because dabigatran has $35 \%$ protein bound and the rest is unbound [14]. Idarucizmab which is monoclonal antibody that can act as antidote and bind to dabigatran and clear it from the circulation within 60 seconds [13].

Bleeding from factor $\mathrm{X}$ an inhibitor cannot treat with dialysis or 
hemofiltration because of tightly bound to the plasma protein and can't be cleared [14] from the circulation. Recombinant human factor $\mathrm{X}$ (andexnet alfa) was approved to reverse bleed due to apixaban and rivaroxaban in life threatening situation, it is an expensive medication and not available in resource limited hospitals. Prothrombin complex is widely used instead, although it is not FDA approved yet [15]. DOACs are not approved and strictly contraindicated in patient with mechanical valves. Patients with antiphospholipid syndrome, in pregnant or breast-feeding women.

\section{Conclusion}

Direct non vitamin $\mathrm{K}$ antagonist are widely prescribed by clinicians for patients who deemed before unsuitable for vitamin $\mathrm{K}$ antagonist because they can't afford to have regular blood monitoring, drug interactions, unpredictive INR, patients who develop complication like skin infarction due to protein $\mathrm{C}$ deficient, or intracranial hemorrhage,

However, ODAC's are not suitable for patients with severe kidney or liver impairment. Although the advantages of DOSCs over warfarin are modest, most guidelines recommend direct oral anticoagulants because they are easy to use and have superior safety over warfarin. Prescribing direct oral anticoagulant for older people with atrial fibrillation and DVT has increased and even for people with risk of non-serious falls [16].

\section{Acknowledgment}

Associate Professor Adel Ekladious want to thank Dr. Eline Ekladious and Niany Ekladious for editing the Manuscript.

\section{References}

1. Connolly SJ, Ezekowitz MD, Yusuf S, Eikelboom J, Oldgren J, et al. (2009) Dabigatran versus Warfarin in Patients with Atrial Fibrillation. N Engl J Med 361: 1139-1151.

2. Hori M, Connolly SJ, Zhu J, Liu LS, Lau CP, et al. (2013) Dabigatran versus warfarin: effects on ischemic and hemorrhagic strokes and bleeding in Asians and non-Asians with atrial fibrillation. Stroke 44: 1891-1896.

3. Hart RG, Pearce LA, Aguilar MI (2007) Meta-analysis: antithrombotic therapy to prevent stroke in patients who have nonvalvular atrial fibrillation. Ann Intern Med 146: 857-867.

4. Fries D, Giurea A, Gütl M, Halbmayer WM, Kozek-Langenecker $S$, et al. (2013) Management of dabigatran-induced bleeding: expert statement. Wien Klin Wochenschr 125: 721-729.
5. Ansell J, Hirsh J, Hylek E, Jacobson A, Crowther M, et al. (2008) Pharmacology and management of the vitamin $K$ antagonists: American College of Chest Physicians Evidence-Based Clinical Practice Guidelines ( $8^{\text {th }}$ Edition). Chest 133: 160S-198S.

6. Eerenberg ES, Kamphuisen PW, Sijpkens MK, Meijers JC, Buller HR, et al. (2011) Reversal of rivaroxaban and dabigatran by prothrombin complex concentrate: a randomized, placebo-controlled, crossover study in healthy subjects. Circulation 124: 1573-1579.

7. Koutsoumpelis A, Argyriou C, Tasopoulou KM, Georgakarakos EI, Georgiadis GS, et al. (2018) Novel Oral Anticoagulants in Peripheral Artery Disease: Current Evidence. Curr Pharm Des 24: 4511-4515.

8. Lewis $B E$, Wallis $D E$, Berkowitz SD, Matthai $W H$, Fareed J, et al. (2001) Argatroban anticoagulant therapy in patients with heparininduced thrombocytopenia. Circulation 103: 1838-1843.

9. Park CS, Choi EK, Kim HM, Lee SR, Cha MJ, et al. (2017) Increased risk of major bleeding in underweight patients with atrial fibrillation who were prescribed non-vitamin $\mathrm{K}$ antagonist oral anticoagulants. Heart Rhythm 14: 501-507.

10. Antonijevic NM, Zivkovic ID, Jovanovic LM, Matic DM, Kocica MJ, et al. (2017) Dabigatran - Metabolism, Pharmacologic Properties and Drug Interactions. Curr Drug Metab 18: 622-635.

11. Chan PH, Hai JJ, Huang D, Ho MH, Chan EW, et al. (2016) Burden of upper gastrointestinal symptoms in patients prescribed dabigatran for stroke prevention. SAGE Open Med 4: 2050312116662414.

12. Lee KN, Choi JI, Boo KY, Kim DY, Kim YG, et al. (2020) Effectiveness and Safety of Off-label Dosing of Non-vitamin K Antagonist Anticoagulant for Atrial Fibrillation in Asian Patients. Sci Rep 10: 1801.

13. Clinical Excellence Commission (2017) NOAC Guidelines Nonvitamin K Antagonist Oral Anticoagulant.

14. Lin S, Wang Y, Zhang L, Guan W (2019) Dabigatran must be used carefully: literature review and recommendations for management of adverse events. Drug Des Devel Ther 13: 1527-1533.

15. Ruff CT, Giugliano RP, Antman EM (2016) Management of Bleeding With Non-Vitamin K Antagonist Oral Anticoagulants in the Era of Specific Reversal Agents. Circulation 134: 248-261.

16. Mitchell A, Welsh TJ, Watson MC, Snowball J, McGrogan A (2019) Use of oral anticoagulants in older people with atrial fibrillation in UK general practice: protocol for a cohort study using the Clinical Practice Research Datalink (CPRD) database. BMJ Open 9: e032646. 